\title{
Chemical burns treated at the Burns Unit in Debrecen, Hungary during the last decade
}

István Juhász', Irén Erdei ${ }^{1,2}$

Burn Unit at Dept. Dermatology, ${ }^{2}$ Dept. Anesthesiology and Intensive Care, Univ. of Debrecen, Debrecen, Hungary

Among burns, chemical burns are usually of lesser extent but tend to be more serious due to the depth of these wounds. Last year we had to treat an increased number of chemical injuries, the most severe among these was a young man with $45 \%$ basic burn injury. In a retrospective study we collected data on patients with chemical burns admitted to our Burn Unit during the last 10 years. During the period of 2007 January $1^{\text {st }}$ and 2016 December $31^{\text {st }}$ we hospitalized 2499 patients with burns, among these 35 patients suffered chemical injuries. This represented $1,44 \%$ of our admissions with a mean age of 39,41 (2-75 years).

\begin{tabular}{|c|c|c|c|c|c|c|c|c|c|c|}
\hline & 2007 & 2008 & 2009 & 2010 & 2011 & 2012 & 2013 & 2014 & 2015 & 2016 \\
\hline $\begin{array}{l}\text { Total } \\
\text { burns/ } \\
\text { years }\end{array}$ & 231 & 142 & 216 & 206 & 229 & 282 & 254 & 268 & 247 & 294 \\
\hline 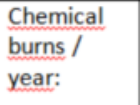 & 2 & 1 & - & 3 & 4 & 3 & 4 & 4 & 4 & 10 \\
\hline $\begin{array}{l}\text { Sex } \\
\text { distribution }\end{array}$ & $\begin{array}{l}1 \text { female } \\
1 \text { male }\end{array}$ & 1 female & & 3 female & 4 male & $\begin{array}{l}2 \text { female } \\
1 \text { male }\end{array}$ & $\begin{array}{l}1 \text { female } \\
3 \text { male }\end{array}$ & $\begin{array}{l}1 \text { female } \\
3 \text { male }\end{array}$ & $\begin{array}{l}1 \text { female } \\
3 \text { male }\end{array}$ & $\begin{array}{l}6 \text { female } \\
4 \text { male }\end{array}$ \\
\hline $\begin{array}{l}\text { Ratio of } \\
\text { chemical } \\
\text { burns: }\end{array}$ & $0,86 \%$ & $0,70 \%$ & & $1,45 \%$ & $1,76 \%$ & $1,06 \%$ & $1,57 \%$ & $1,49 \%$ & $1,61 \%$ & $3,40 \%$ \\
\hline
\end{tabular}

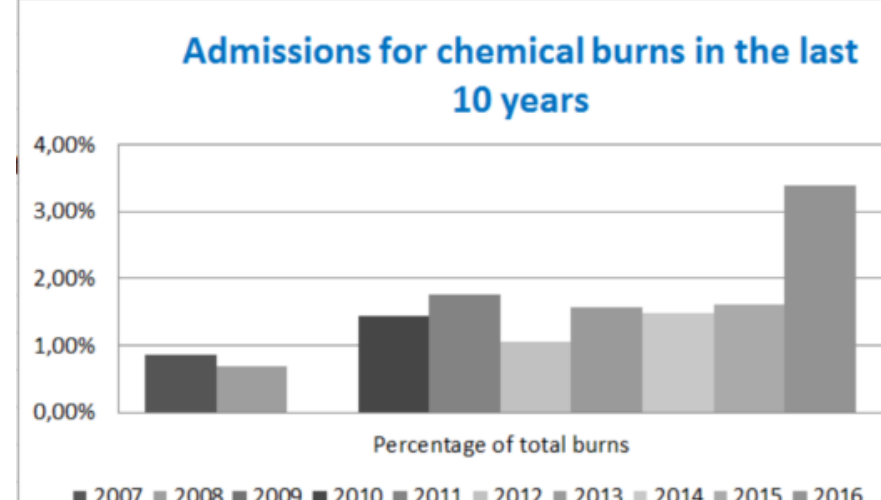

Extent of the injuries were in the range of $1-45 \%$ TBSA with an average extent of $4,6 \%$. The hands were the most common involved body site. The injuries required surgical treatment in 26 patients (74\%). There was a slight male dominance among the victims (16 female / 19 male patients). Most accidents occurred in the domestic setting, only 5 out of $35(14 \%)$ happened at the workplace. We observed an increase in the incidence of corrosive injuries over time at least in the region served by our center. Among the causes of chemical burns requiring admission liquids with basic $\mathrm{Ph}$ were more common than acids. Among these liquid de-greasers could be identified as the most common single causative agent in our cohort.

We present 3 cases of chemical burns in order to demonstrate the complexity of the diagnosis and treatment of corrosive burns.

Pt \#1

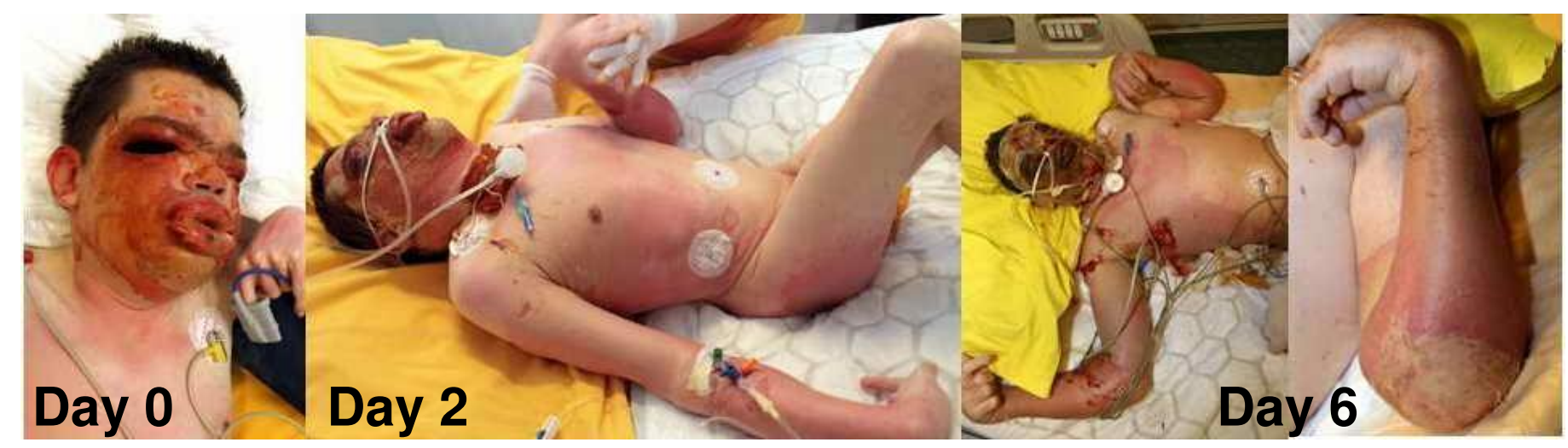

Progressive neck- and laryngeal edema mandated tracheostomy, and ventillation therapy was initiated. Repeated flushing of the involved areas was carried out and serial necrectomies performed with subsequent autologous STSG coverage on the trunk, both arms, forearms and face and neck. (Altogether 3 operations were carried out, first surgery was done on day 7.) He was released from the ICU after 27 days and released home 12 days later.

A $34 \mathrm{yr}$ old retarded male, a nursing home resident was rushed to our department with extreme facial edema and redness, together with seropapules and large epidermolytic blisters /denuded erosions on the trunk and upper extremities. Initial diagnosis was TEN, but skin lesions rapidly progressed into edematous necrotic plaques and Ph-indicator testing of the skin surface revealed strong basic environment (without any anamnestic clue)..

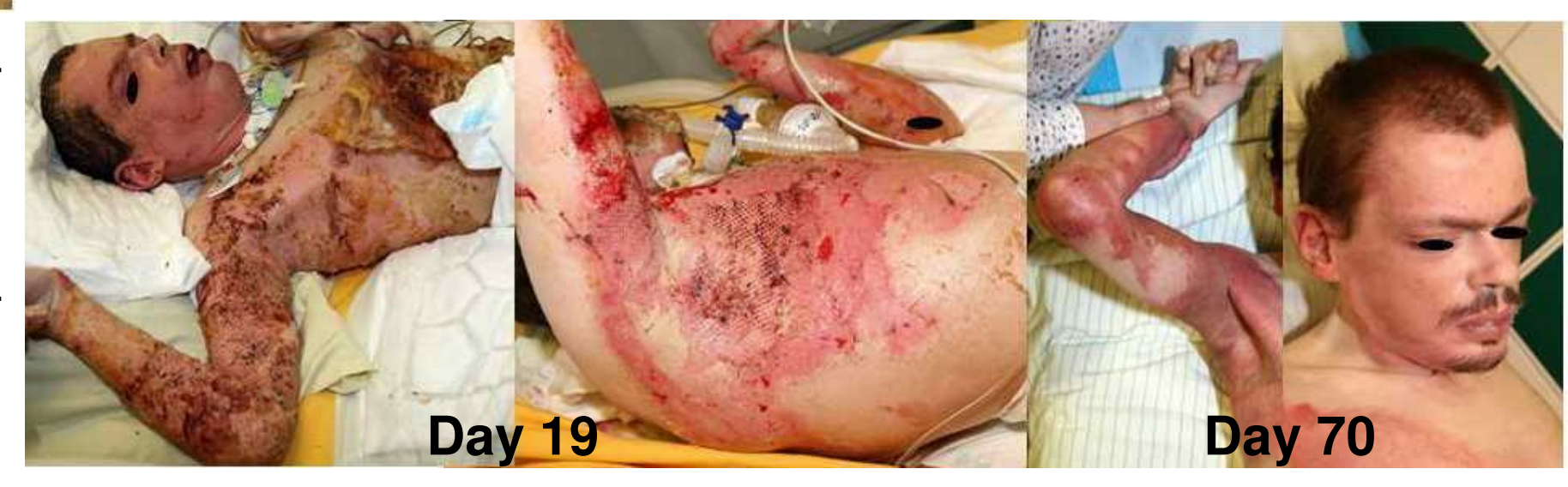

\section{Pt \#2}

An 80 year old male tumbled while working in his garden with cold degreaser. The substance poured on his right arm and forearm. He was admitted one week later with necrotic upper extremity wounds. He consented to have
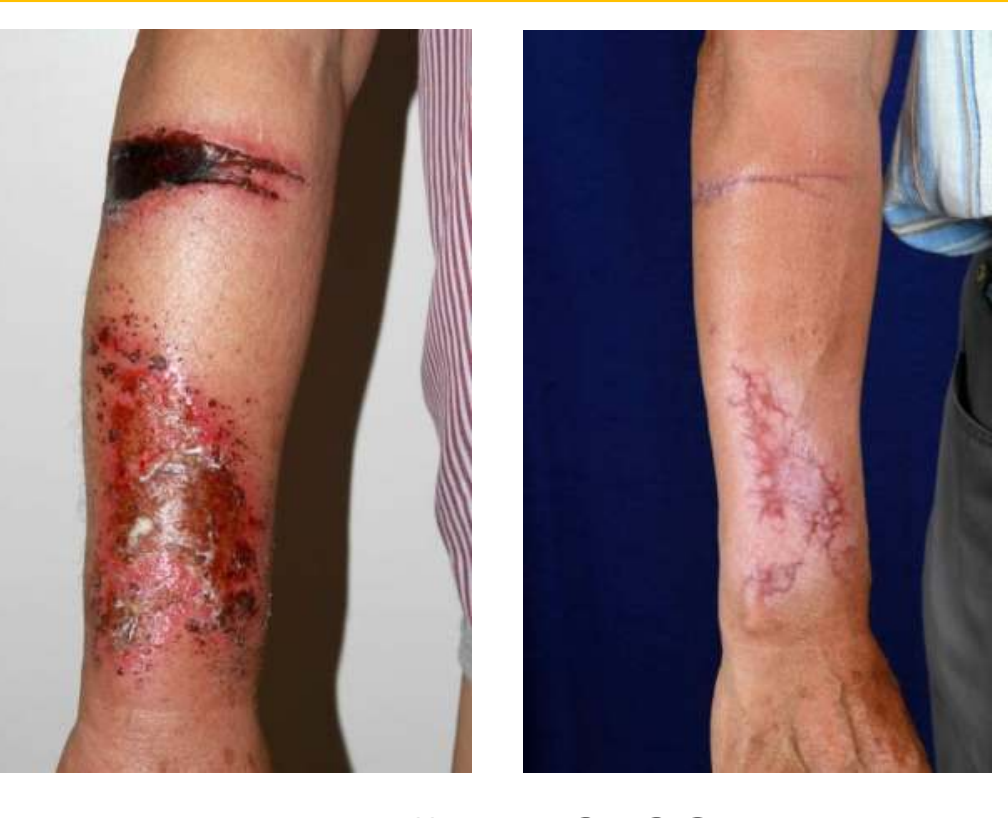

debridement /escharectomy but rejected the offered STSG closure. He was released home and conservative wound care was carried out by community outpatient service. He presented with mild hypertrophic scars upon control exam.

\section{Pt \#3}

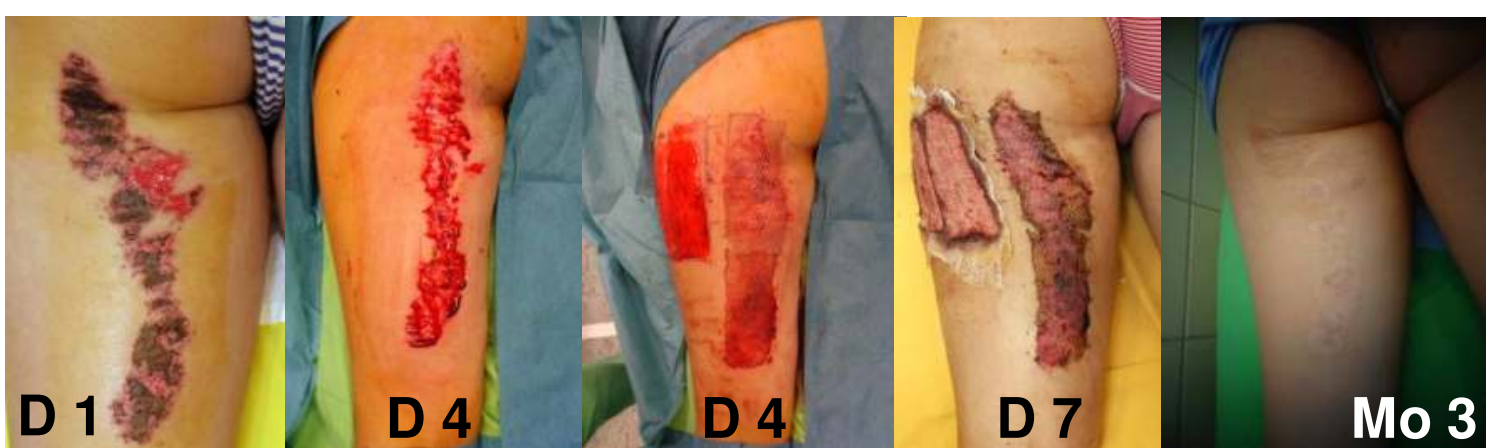

A $17 \mathrm{yr}$ old girl while traveling on a train felt her seat was wet and on her left buttock and posterior flank she had a stinging sensation. On same day she was admitted with $2 \mathrm{~B}-3^{\text {rd }}$ degree burns on that area. $\mathrm{Ph}$ testing confirmed presence of strong basic substance. On day 4 post burn a full necrectomy and STSG coverage was carried out. Forensic exam of the soaked/burned clothing did not reveal what the substance was. Complete graft take and acceptable scarring was observed upon control exam.

Based on the presented data, there seems to be an increase in chemical injuries. This is in opposition to trends in incidence of burn injuries in general, with its cause unknown to us. Bases cause colliquative necrosis as opposed to acids, which could serve as an obvious explanation why there are more severe cases requiring hospitalization among such burns. We also figured that more and more households use cold degreasers which is a strong basic substance. It is also noteworthy that these increasing numbers still represent the lower threshold of incidence among burn admissions when compared to data from the literature $(1,4-8.5 \%)$.

\section{References:}

Agbenorku P, Akpaloo J et Al: Chemical Burn Injury in Kumasi: The Trend and Complications following and Their Management. Plast Reconstr Surg Glob Open. 2015 Oct 23;3(10):e548

Koh DH, Lee SG, Kim HC. Incidence and characteristics of chemical burns. Burns. 2017 May;43(3):654-664

Maghsoudi H, Gabraely N. Epidemiology and outcome of 121 cases of chemical burn in East Azarbaijan province, Iran. Injury 2008;39:1042-6.

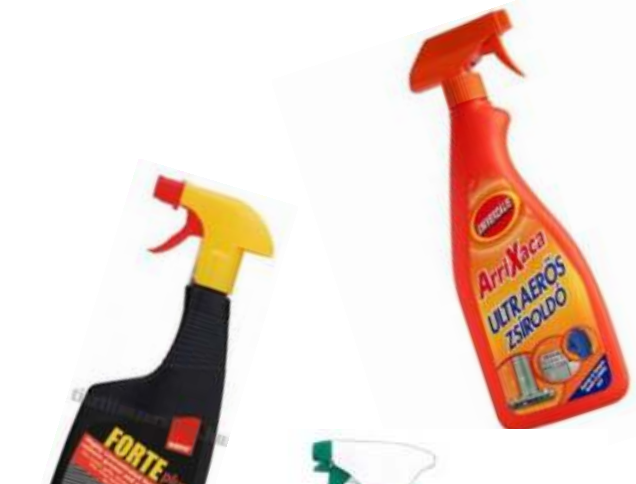

